\title{
Fox-Amphoux - La Jeansarde
}

\section{Florence Parent et Corinne Bouttevin}

Édition électronique
URL : http://journals.openedition.org/adlfi/6535

ISSN : 2114-0502

Éditeur

Ministère de la culture

Référence électronique

Florence Parent et Corinne Bouttevin, «Fox-Amphoux - La Jeansarde », ADLFI. Archéologie de la France - Informations [En ligne], Provence-Alpes-Côte d'Azur, mis en ligne le 01 mars 2007, consulté le 01 mai 2019. URL : http://journals.openedition.org/adlfi/6535

Ce document a été généré automatiquement le 1 mai 2019.

(c) Ministère de la Culture et de la Communication, CNRS 


\title{
Fox-Amphoux - La Jeansarde
}

\author{
Florence Parent et Corinne Bouttevin
}

Identifiant de l'opération archéologique : 8037

Date de l'opération : 2007 (EX)

Inventeur(s) : Parent Florence (INRAP) ; Bouttevin Corinne (INRAP)

1 Une demande d'autorisation de lotir, au lieu-dit La Jeansarde, à Fox-Amphoux, a motivé la prescription d'un diagnostic archéologique, sur une parcelle d'une superficie de $11785 \mathrm{~m}^{2}$

2 La commune de Fox-Amphoux est située à une trentaine de kilomètres au nord de SaintMaximin et à une vingtaine de Brignoles. De nombreux sites y sont déjà recensés (Brun, 1999: 411-417) : habitats de l'âge du Fer perchés ou en plaine, villae et habitats ruraux d'époque romaine et temple, sépultures romaines à proximité du site de diagnostic, ainsi qu'une chapelle médiévale.

3 L'opération, d'une durée de trois jours, s'est déroulée en juillet 2007 et dix-sept sondages ont été ouverts à l'aide d'une pelle mécanique. Le substrat rocheux a été atteint très rapidement dans toutes les tranchées. Il se présente soit sous forme de calcaire dur, formant des bancs rocheux «fissurés ", entre lesquels les colluvions se sont immiscées, soit sous forme de calcaire tendre très érodé. Les deux faciès peuvent se rencontrer dans une même tranchée. Ce substrat est recouvert par une couche de limons brun clair, mêlés de cailloux et cailloutis calcaire, pouvant être assimilés à des colluvions. Ces limons, dont l'épaisseur de sédimentation varie de $0 \mathrm{~m}$ en haut de pente (rocher affleurant) à 0,30-0,35 m à mi-pente, n'ont livré aucun mobilier archéologique, de quelque période que ce soit.

4 Dans les tranchées 5 et 15 , la surface du substrat calcaire révèle des traces agraires longilignes (sillons), vraisemblablement récentes, au vu de leur position stratigraphique.

5 Seule la tranchée 2 a livré les restes d'une sépulture, accompagnée d'un dépôt de céramiques, datées du premier âge du Fer, dont une urne archéologiquement complète de type CNT-PRO U4a (Arcelin, 1993 : 324), à l'épaulement peu marqué souligné d'une ligne 
de poinçons triangulaires. Si d'autres sépultures ont existé à cet endroit, aucune ne subsiste. En effet, comme le montrent les autres sondages, le site a subi une très forte érosion, qui en aura fait disparaitre toute trace. Notre découverte a sans doute été préservée uniquement car elle entaillait légèrement le substrat rocheux. Nous ne sommes donc pas en mesure de déterminer s'il s'agit d'une tombe isolée ou des maigres vestiges d'une nécropole protohistorique.

PARENT Florence et BOUTTEVIN Corinne

INDEX

operation Expertise (EX)

Index géographique : Provence-Alpes-Côte d'Azur, Var (83), Fox-Amphoux

Index chronologique : âge du Fer, Empire romain

\section{AUTEURS}

FLORENCE PARENT

INRAP

CORINNE BOUTTEVIN

INRAP 